Digitized by the Internet Archive in 2007 with funding from Microsoft Corporation 
ILUSTRATIONS OF THE HERBERT SPENCER LECTURE 1907.

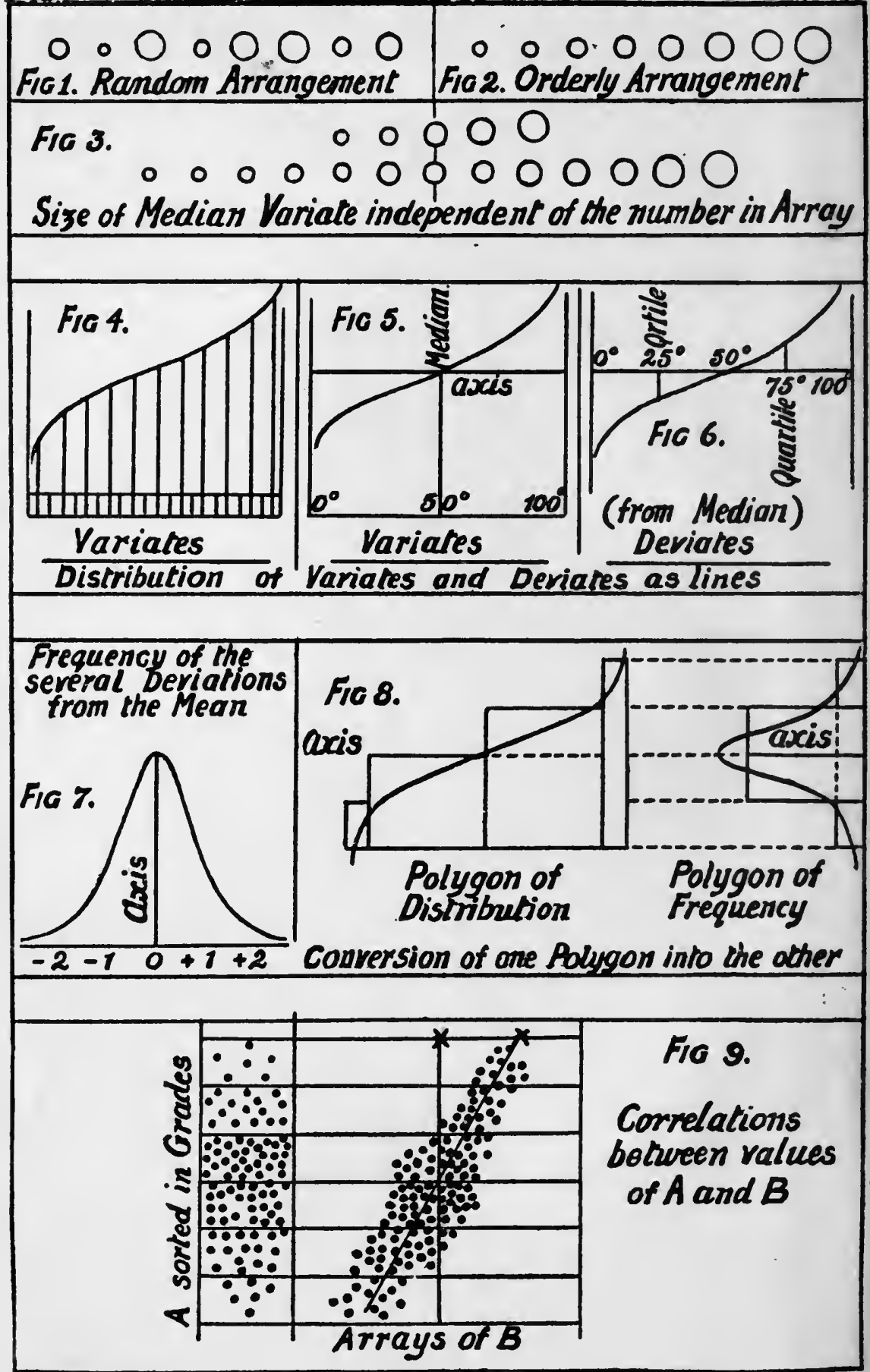



HENRY FROWDE, M.A.

PUBLISHRR TO THE UNIVERSITY OF OXFORD

LONDON, EDINBURGH

NEW YORK AND TORONTO 


\section{PROBABILITY, THE FOUNDATION OF EUGENICS}

THE request so honourable to myself, to be the Herbert Spencer lecturer of this year, aroused a multitude of vivid recollections. Spencer's strong personality, his complete devotion to a self-imposed and life-long task, together with rare gleams of tenderness visible amidst a wilderness of abstract thought, have left a unique impression on my mind that years fail to weaken.

I do not propose to speak of his writings; they have been fully commented on elsewhere, but I desire to acknowledge my personal debt to him, which is large. It lies in what I gained through his readiness to discuss any ideas I happened to be full of at the time, with quick sympathy and keen criticism. It was his custom for many afternoons to spend an hour or two of rest in the old smoking room of the Athenaeum Club, strolling into an adjoining compartment for a game of billiards when the table was free. Day after day on those afternoons I enjoyed brief talks with him, which were often of exceptional interest to myself. All that kind of comfort and pleasure has long ago passed from 
me. Among the many things of which age deprives us, I regret few more than the loss of contemporaries. When I was young I felt diffident in the presence of my seniors, partly owing to a sense that the ideas of the young cannot be in complete sympathy with those of the old. Now that I myself am old it seems to me that my much younger friends keenly perceive the same difference, and I lose much of that outspoken criticism which is an invaluable help to all who investigate.

\section{History of Eugenics.}

It must have surprised you as it did myself to find the new word 'Eugenics' in the title both of the Boyle lecture, delivered in Oxford about a fortnight ago, and of this. It was an accident, not a deliberate concurrence, and I accept it as a happy omen. The field of Eugenics is so wide that there is no need for myself, the second lecturer, to plant my feet in the footsteps of the first; on the contrary, it gives freedom by absolving me from saying much that had to be said in one way or another. I fully concur in the views so ably presented by my friend and co-adjutor Professor Karl Pearson, and am glad to be dispensed from further allusion to subjects that formed a large portion of his lecture, on which he is a far better guide and an infinitely higher authority than myself.

In giving the following sketch of the history of Eugenics I am obliged to be egotistical, because I 
kindled the feeble flame that struggled doubtfully for a time until it caught hold of adjacent stores of suitable material, and became a brisk fire, burning freely by itself, and again because I have had much to do with its progress quite recently.

The word 'Eugenics' was coined and used by me in my book Human Faculty, published as long ago as I883, which has long been out of print; it is, however, soon to be re-published in a cheap form. In it I emphasized the essential brotherhood of mankind, heredity being to my mind a very real thing; also the belief that we are born to act, and not to wait for help like able-bodied idlers, whining for doles. Individuals appear to me as finite detachments from an infinite ocean of being, temporarily endowed with executive powers. This is the only answer I can give to myself in reply to the perpetually recurring questions of 'Why? whence? and whither?' The immediate 'whither?' does not seem wholly dark, as some little information may be gleaned concerning the direction in which Nature, so far as we know of it, is now moving. Namely towards the evolution of mind, body, and character in increasing energy and co-adaptation.

I have often wondered that the poem of Hyperion, by Keats-that magnificent torso of an incompleted work-has not been placed in the very forefront of past speculations on evolution. Keats is so thorough that he makes the very Divinities to be its product. The earliest gods such as Coelus, born out of Chaos, 
are vague entities, they engender Saturn, Oceanus, Hyperion, and the Titan brood, who supersede them. These in their turn are ousted from dominion by their own issue, the Olympian Gods. A notable advance occurs at each successive stage in the quality of the Divinities. When Hyperion, newly terrified by signs of impending overthrow, lies prostrate on the earth ' his ancient mother, for some comfort yet,' the voice of Coelus from the universal space, thus 'whispered low and solemn in his ear ... yet do thou strive for thou art capable ... my life is but the life of winds and tides, no more than winds and tides can I prevail, but thou canst.' I have quoted only disjointed fragments of this wonderful poem, enough to serve as a reminder to those who know it, but will add ten consecutive lines from the speech of the fallen Oceanus to his comrades, which give a summary of evolution as here described:

As Heaven and Earth are fairer, fairer far Than Chaos and black Darkness, though once chiefs, And as we show beyond that Heaven and Earth In form and shape compact and beautiful, In Will, in action free, companionship, And thousand other signs of purer life; So on our heels a fresh perfection treads A power more strong in beauty, born of us And fated to excel us, as we pass In glory that old Darkness.

He ends with 'this is the truth, and let it be your balm.' The poem is a noble conception, founded on the crude cosmogony of the ancient Greeks. 
The ideas have long held my fancy that we men may be the chief, and perhaps the only executives on earth. That we are detached on active service with, it may be only illusory, powers of free-will. Also that we are in some way accountable for our success or failure to further certain obscure ends, to be guessed as best we can. That though our instructions are obscure they are sufficiently clear to justify our interference with the pitiless course of Nature, whenever it seems possible to attain the goal towards which it moves, by gentler and kindlier ways. I expressed these views as forcibly as I then could in the above-mentioned book, with especial reference to improving the racial qualities of mankind, in which the truest piety seems to me to reside in taking action, and not in submissive acquiescence to the routine of Nature. It was thought impious at one time to attach lightning conductors to churches, as showing a want of trust in the tutelary care of the Deity to whom they were dedicated; now I think most persons would be inclined to apply some contemptuous epithet to such as obstinately refused, on those grounds, to erect them.

The direct pursuit of studies in Eugenics, as to what could practically be done, and the amount of change in racial qualities that could reasonably be anticipated, did not at first attract investigators. The idea of effecting an improvement in that direction was too much in advance of the march of popular imagination, so $I$ had to wait. In the meantime I occupied myself with collateral problems, more especially with that of dealing 
measurably with faculties that are variously distributed in a large population. The results were published in my 'Natural Inheritance' in I889, and I shall have occasion to utilize some of them later on, in this very lecture. The publication of that book proved to be more timely than the former. The methods were greatly elaborated by Professor Karl Pearson, and applied by him to Biometry. Professor Weldon of this University, whose untimely death is widely deplored, aided powerfully. A new science was thus created primarily on behalf of Biometry, but equally applicable to Eugenics, because their provinces overlap.

The publication of Biometrika, in which I took little more than a nominal part, appeared in Igor.

Being myself appointed Huxley Lecturer before the Anthropological Institute in Igor I took for my title ' The possible improvement of the Human Breed under the existing conditions of Law and Sentiment' (Nature, November I, Igor, Report of the Smithsonian Institute, Washington, for the same year).

The next and a very important step towards Eugenics was made by Professor Karl Pearson in his Huxley lecture of 1903 entitled 'The Laws of Inheritance in Man' (Biometrika, vol. iii). It contains a most valuable compendium of work achieved and of objects in view; also the following passage (p. I59), which is preceded by forcible reasons for his conclusions:

We are ceasing as a nation to breed intelligence as we did fifty to a hundred years ago. The mentally 
better stock in the nation is not reproducing itself at the same rate as it did of old; the less able, and the less energetic are more fertile than the better stocks. No scheme of wider or more thorough education will bring up, in the scale of intelligence, hereditary weakness to the level of hereditary strength. The only remedy, if one be possible at all, is to alter the relative fertility of the good and the bad stocks in the community.

Again in 1904, having been asked by the newly-formed Sociological Society to contribute a memoir, I did so on 'Eugenics, its definition, aim, and scope'. This was followed up in 1905 by three memoirs, 'Restrictions in Marriage,' 'Studies in National Eugenics,' and 'Eugenics as a factor in Religion', which were published in the Memoirs of that Society with comments thereon by more than twenty different authorities (Sociological Papers, published for the Sociological Society (Macmillan), vols. $i$ and ii). The subject of Eugenics being thus formally launched, and the time appearing ripe, I offered a small endowment to the University of London to found a Research Fellowship on its behalf. The offer was cordially accepted, so Eugenics gained the recognition of its importance by the University of London, and a home for its study in University College. Mr. Edgar Schuster, of this University, became Research Fellow in 1905, and I am much indebted to his care in nurturing the young undertaking and for the memoirs he has contributed, part of which must remain for a short time longer unpublished. 
When the date for Mr. Schuster's retirement approached it was advisable to utilize the experience so far gained in reorganizing the Office. Professor Pearson and myself, in consultation with the authorities of the University of London, elaborated a scheme at the beginning of this year, which is a decided advance, and shows every sign of vitality and endurance. $\mathrm{Mr}$. David Heron, a Mathematical Scholar of St. Andrews, is now a Research Fellow; Miss Ethel Elderton, who has done excellent and expert work from the beginning, is deservedly raised to the position of Research Scholar; and the partial services of a trained Computer have been secured. An event of the highest importance to the future of the Office is that Professor Karl Pearson has undertaken, at my urgent request, that general supervision of its work which advancing age and infirmities preclude me from giving. He will, I trust, treat it much as an annexe to his adjacent biometric laboratory, for many studies in Eugenics might, with equal propriety, be carried on in either of them, and the same methods of precise analysis which are due to the mathematical skill and untiring energy of Professor Pearson are used in both. The Office now bears the name of the Eugenics Laboratory, and its temporary home is in 88 Gower Street. The phrase 'National Eugenics' is defined as 'the study of agencies under social control that may improve or impair the racial qualities of future generations, either physically or mentally'. 
The Laboratory has already begun to publish memoirs on its own account, and I now rest satisfied in the belief that, with a fair share of good luck, this young Institution will prosper and grow into an important centre of research.

\section{Application of Theories of Probability to Eugenics.}

Eugenics seeks for quantitative results. It is not contented with such vague words as 'much ' or 'little', but endeavours to determine 'how much' or 'how little' in precise and trustworthy figures. A simple example will show the importance of this. Let us suppose a class of persons, called $A$, who are afflicted with some form and some specified degree of degeneracy, as inferred from personal observations, and from family history, and let class $B$ consist of the offspring of $A$. We already know only too well that when the grade of $A$ is very low, that of the average $B$ will be below par and mischievous to the community, but how mischievous will it probably be? This question is of a familiar kind, easily to be answered when a sufficiency of facts have been collected. But a second question arises, What will be the trustworthiness of the forecast derived from averages when it is applied to individuals? This is a kind of question that is not familiar, and rarely taken into account, although it too could be answered easily as follows. The average mischief done by each $B$ individual to the community may for 
brevity be called $M$ : the mischiefs done by the several individuals differ more or less from $M$ by amounts whose average may be called $D$. In other words $D$ is the average amount of the individual deviations from $M$. $D$ thus becomes the measure of untrustworthiness. The smaller $D$ is, the more precise the forecast, and the stronger the justification for taking such drastic measures against the propagation of class $B$ as would be consonant to the feelings if the forecast were known to be infallible. On the other hand, a large $D$ signifies a corresponding degree of uncertainty, and a risk that might be faced without reproach through a sentiment akin to that expressed in the maxim 'It is better that many guilty should escape than that one innocent person should suffer'. But that is not the sentiment by which natural selection is guided, and it is dangerous to yield far to it.

There can be no doubt that a thorough investigation, of the kind described, even if confined to a single grade and to a single form of degeneracy, would be a serious undertaking. Masses of trustworthy material must be collected, usually with great difficulty, and be afterwards treated with skill and labour by methods that few at present are competent to employ. An extended investigation into the good or evil done to the state by the offspring of many different classes of persons, some of civic value, others the reverse, implies a huge volume. of work sufficient to occupy Eugenics laboratories for an indefinite time. 
Object Lessons in the Methods of Biometry.

I propose now to speak of those fundamental principles of the laws of Probability that are chiefly concerned in the newer methods of Biometry, and consequently of Eugenics. Most persons of ordinary education seem to know nothing about them, not even understanding their technical terms, much less appreciating the cogency of their results. This popular ignorance so obstructs the path of Eugenics that I venture to tax your attention by proposing a method of partly dispelling it. Let me first say that no one can be more conscious than myself of the large amount of study that is required to qualify. a man to deal adequately with the mathematical methods of Biometry, or that any man can hope for much success in that direction unless he is possessed of appropriate faculties and a strong brain. On the other hand, I hold an opinion likely at first sight to scandalize biome. tricians and which I must justify, that the fundamental ideas on which abstruse problems of Probability are based admit of being so presented to any intelligent person as to be grasped by him, even though he be quite ignorant of mathematics. The conditions of doing so are that the lessons shall be as far as possible 'Object lessons', in which real objects shall be handled as in the Kindergarten system, and simple operations performed and not only talked about. I am anxious to make myself so far understood, that some teachers of science may be induced to elaborate the course that I present now 
only in outline. It seems to me suitably divisible into a course of five lessons of one hour each, which would be sufficient to introduce the learner into a new world of ideas, extraordinarily wide in their application. A proper notion of what is meant by Correlation requires some knowledge of the principal features of Variation, and will be the goal towards which the lessons lead.

To most persons Variability implies something indefinite and capricious. They require to be taught that it, like Proteus in the old fable, can be seized, securely bound, and utilized; that it can be defined and measured. It was disregarded by the old methods of statistics, that concerned themselves solely with Averages. The average amount of various measurable faculties or events in a multitude of persons was determined by simple methods, the individual variations being left out of account as too difficult to deal with. A population was treated by the old methods as a structureless atom, but the newer methods treat it as a compound unit. It will be a considerable intellectual gain to an otherwise educated person, to fully understand the way in which this can be done, and this and such like matters the proposed course of lessons is intended to make clear. It cannot be expected that in the few available minutes more than an outline can be given here of what is intended to be conveyed in perhaps thirty-fold as much time with the aid of profuse illustrations by objects and diagrams. At the risk of being wearisome, it is, however, necessary to offer the following syllabus 
of what is proposed, for an outline of what teachers might fill in.

The object of the first lesson would be to explain and illustrate Variability of Size, Weight, Number, \&c., by exhibiting samples of specimens that had been marshalled at random (Fig. I), or arrayed in order of their magnitude (Fig. 2). Thus when variations of length were considered, objects of suitable size, such as chestnuts, acorns, hazel-nuts, stones of wall fruit, might be arrayed as beads on a string. It will be shown that an 'Array' of Variates of any kind falls into a continuous series. That each variate differs little from its neighbours about the middles of the Arrays, but that such differences increase rapidly towards their extremities. Abundant illustration would be required, and much handling of specimens.

Arrays of Variates of the same class strung together, differing considerably in the number of the objects they each contain, would be laid side by side and their middle, most variates or 'Medians' (Fig. 3) would be compared. It would be shown that as a rule the Medians become very similar to one another when the numbers in the Arrays are large. It must then be dogmatically explained that double accuracy usually accompanies a four-fold number, a treble accuracy a nine-fold number, and so on.

(This concludes the first lesson, during which the words and significations of Variability, Variate, Array, and Median will have been learnt.) 
The second lesson is intended to give more precision to the idea of an Array. The variates in any one of these strung loosely on a cord, should be disposed at equal distances apart in front of an equal number of compartments, like horses in the front of a row of stalls (Fig. 4), and their tops joined. There will always be one more side to the row of stalls than there are objects, otherwise a side of one of the extreme stalls would be wanting. Thus there are two ways of indicating the portion of a particular variate, either by its serial number as 'first', 'second', 'third', or so on, or by degrees like those of a thermometer. In the latter case the sides of the stalls serve as degrees, counting the first of them as $0^{\circ}$, making one more graduation than the number of objects, as should be. The difference between these two methods has to be made clear, and that while the serial position of the Median object is always the same in any two Arrays whatever be the number of variates, the serial positions of their subdivisions cannot be the same, the ignored half interval at either end varying in width according to the number of variates, and becoming considerable when that number is small.

Lines of proportionate length will then be used drawn on a black board, and the limits of the Array will be also drawn, at a half interval from either end. The base is then to be divided centesimally.

Next join the tops of the lines with a smooth curve, and wipe out everything except the curve, the Limit at either side, and the Centesimally divided Base (Fig. 5). 
This figure forms a Scheme of Distribution of Variates. Explain clearly that its shape is independent of the number of Variates, so long as they are sufficiently numerous to secure statistical constancy.

Show numerous schemes of variates of different kinds, and remark on the prevalent family likeness between the bounding curves. (Words and meanings learnt-Schemes of Distribution, Centesimal graduation of base.)

The third lesson passes from Variates, measured upwards from the base, to Deviates measured upwards or downwards from the Median, and treated as positive or negative values accordingly (Fig. 6).

Draw a Scheme of Variates on the black board, and show that it consists of two parts; the median which represents a constant, and the curve which represents the variations from it. Draw a horizontal line from limit to limit, through the top of the Median, to serve as Axis to the Curve. Divide the Axis centesimally, and wipe out everything except Curve, Axis, and Limits. This forms a Scheme of Distribution of Deviates. Draw ordinates from the axis to the curve at the $25^{\text {th }}$ and $75^{\text {th }}$ divisions. These are the 'Quartile' deviates.

At this stage the Genesis of the theoretical Normal curve might be briefly explained and the generality of its application; also some of its beautiful properties of reproduction. Many of the diagrams already shown would be again employed to show the prevalence of approximately normal distributions. Exceptions of 
strongly marked Skew curves would be exhibited and their genesis briefly explained.

It will then be explained that while the ordinate at any specified centesimal division in two normal curves measures their relative variability, the Quartile is commonly employed as the unit of variability under the almost grotesque name of 'Probable Error', which is intended to signify that the length of any Deviate in the system is as likely as not to exceed or to fall short of it: This, by construction, is the case of either Quartile.

(New words and meanings-Scheme of Distribution of Deviates, Axis, Normal, Skew, Quartile, and Probable Error.)

In the fourth lesson it has to be explained that the Curve of Normal Distribution is not the direct result of calculation, neither does the formula that expresses it lend itself so freely to further calculation, as that of Frequency. Their shapes differ ; the first is an Ogive, the second (Fig. 7) is Bell-shaped. In the curve of Frequency the Deviations are reckoned from the Mean of all the Variates, and not from the Median. Mean and Median are the same in Normal Curves, but may differ much in others. Either curve can be transformed into the other, as is best exemplified by using a Polygon (Fig. 8) instead of the Curve, consisting of a series of rectangles differing in height by the same amounts, but having widths respectively representative of the frequencies of $I, 3,3, \mathbf{I}$. (This is one of those known as a binomial series, whose 
genesis might be briefly explained.) If these rectangles are arrayed in order of their widths, side by side, they become the equivalents of the ogival curve of Distribution. Now if each of these latter rectangles be slid parallel to itself up to either limit, their bases will overlap and they become equivalent to the bell-shaped curve of Frequency with its base vertical.

The curve of Frequency contains no easily perceived unit of variability like the Quartile of the Curve of Distribution. It is therefore not suited for and was not used as a first illustration, but the formula that expresses it is by far the more suitable of the two for calculation. Its unit of variability is what is called the 'Standard Deviation,' whose genesis will admit of illustration. How the calculations are made for finding its value is beyond the reach of the present lessons. The calculated ordinates of the normal curve must be accepted by the learner much as the time of day by his watch, though he be ignorant of the principles of its construction. Much more beyond his reach are the formulae used to express quasi-normal and skew curves. They require a previous knowledge of rather advanced mathematics.

(New words and ideas-Curve of Frequency, Standard Deviation, Mean, Binomial Series.)

The fifth and last lesson deals with the measurement of Correlation, that is, with the closeness of the relation between any two systems whose variations are due partly to causes common to both, and partly to causes 
special to each. It applies to nearly every social relation, as to environment and health, social position and fertility, the kinship of parent to child, of uncle to nephew, \&c. It may be mechanically illustrated by the movements of two pulleys with weights attached, suspended from a cord held by one of the hands of three different persons, $I, 2$, and 3 . No. 2 holds the middle of the cord, one half of which then passes round one of the pulleys up to the hand of No. I; the other half similarly round the other pulley up to the hand of No. 3. The hands of Nos. I, 2 and 3 move up and down quite independently, but as the movements of both weights are simultaneously controlled in part by No. 2, they become 'correlated'.

The formation of a table of correlations on paper ruled in squares, is easily explained on the blackboard (Fig. 9). The pairs of correlated values $A$ and $B$ have to be expressed in units of their respective variabilities. They are then sorted into the squares of the paper,vertically according to the magnitudes of $A$, horizontally according to those of $B$-, and the Mean of each partial array of $B$ values, corresponding to each grade of $A$, has to be determined. It is found theoretically that where variability is normal, the Means of $B$ lie practically in a straight line on the face of the Table, and observation shows they do so in most other cases. It follows that the average deviation of a $B$ value bears a constant ratio to the deviation of the corresponding $A$ value. This ratio is called the 'Index of Correlation', 
and is expressed by a single figure. For example: if the thigh-bone of many persons deviate 'very much' from the usual length of the thigh-bones of their race, the average of the lengths of the corresponding armbones will differ 'much', but not 'very much', from the usual length of arm-bones, and the ratio between this 'very much' and 'much' is constant and in the same direction, whatever be the numerical value attached to the word 'very much'. Lastly, the trustworthiness of the Index of Correlation, when applied to individual cases, is readily calculable. When the closeness of correlation is absolute, it is expressed by the number $\mathrm{I} \cdot 0$, and by $0 \cdot 0$, when the correlation is nil.

(New words and ideas-Correlation and Index of Correlation.)

This concludes what I have to say on these suggested Object lessons. It will have been tedious to follow in its necessarily much compressed form but will serve, I trust, to convey its main purpose of showing that a very brief course of lessons, copiously illustrated by diagrams and objects to handle, would give an acceptable introduction to the newer methods employed in Biometry and in Eugenics. Further, that when read leisurely by experts in its printed form, it would give quite sufficient guidance for elaborating details. 


\section{Influence of Collective Truths upon Individual Conduct.}

We have thus far been concerned with Probability, determined by methods that take cognizance of Variations, and yield exact results, thereby affording a solid foundation for action. But the stage on which human action takes place is a superstructure into which emotion enters, we are' guided on it less by Certainty and by Probability than by Assurance to a greater or lesser degree. The word Assurance is derived from sure, which itself is an abbreviation of secure, that is of se- cura, or without misgiving. It is a contented attitude of mind largely dependent on custom, prejudice, or other unreasonable influences which reformers have to overcome, and some of which they are apt to utilize on their own behalf. Human nature is such that we rarely find our way by the pure light of reason, but while peering through spectacles furnished with coloured and distorting glasses.

Locke seems to confound certainty with assurance in his forcible description of the way in which men are guided in their daily affairs (Human Understanding, iv, I4, par. r):

Man would be at a great loss if he had nothing to direct him but what has the certainty of true knowledge. For that being very short and scanty, he would be often utterly in the dark, and in most of the actions of his life, perfectly at a stand, had he nothing to guide 
him in the absence of clear and certain knowledge. He that will not eat till he has demonstration that it will nourish him, he that will not stir till he infallibly knows the business he goes about will succeed, will have little else to do but to sit still and perish.

A society may be considered as a highly complex organism, with a consciousness of its own, caring only for itself, establishing regulations and customs for its collective advantage, and creating a code of opinions to subserve that end. It is hard to over-rate its power over the individual in regard to any obvious particular on which it emphatically insists. I trust in some future time that one of those particulars will be the practice of Eugenics. Otherwise the influence of collective truths on individual conduct is deplorably weak, as expressed by the lines:-

For others' follies teach us not, Nor much their wisdom teaches, But chief of solid worth is what Our own experience preaches.

Professor Westermark, among many other remarks in which I fully concur, has aptly stated (Sociological Papers, published for the Sociological Society. Macmillan, 1906, vol. ii, p. 24), with reference to one obstacle which prevents individuals from perceiving the importance of Eugenics, 'the prevalent opinion that almost anybody is good enough to marry is chiefly due to the fact that in this case, cause and effect, marriage and the feebleness of the offspring, are so -distant from each other that the near-sighted eye does 
not distinctly perceive the connexion between them.' (The Italics are mine.)

The enlightenment of individuals is a necessary preamble to practical Eugenics, but social opinion is the tyrant by whose praise or blame the principles of Eugenics may be expected hereafter to influence individual conduct. Public opinion may, however, be easily directed into different channels by opportune pressure. A common conviction that change in the established order of some particular codes of conduct would be impossible, because of the shock that the idea of doing so gives to our present ideas, bears some resemblance to the conviction of lovers that their present sentiments will endure for ever. Conviction, which is that very Assurance of which mention has just been made, is proved by reiterated experience to be a highly fallacious guide. Love is notoriously fickle in despite of the fervent and genuine protestations of lovers, and so is public opinion. I gave a list of extraordinary variations of the latter in respect to restrictions it enforced on the freedom of marriage, at various times and places (Sociological Papers, quoted above). Much could be added to that list, but I will not now discuss the effects of public opinion on such a serious question. I will take a much smaller instance which occurred before the time to which the recollections of most persons can now reach, but which I myself recall vividly. It is the simple matter of hair on the face of male adults. When I was young, it was an unpardonable offence for any English person other than 
a cavalry officer, or perhaps some one of high social rank, to wear a moustache. Foreigners did so and were tolerated, otherwise the assumption of a moustache was in popular opinion worse than wicked, for it was atrociously bad style. Then came the Crimean War and the winter of Balaclava, during which it was cruel to compel the infantry to shave themselves every morning. So their beards began to grow, and this broke a long established custom. On the return of the army to England the fashion of beards spread among the laity, but stopped short of the clergy. These, however, soon began to show dissatisfaction, they said the beard was a sign of manliness that ought not to be suppressed and so forth ; and at length the moment arrived. A distinguished clergyman, happily still living, 'bearded' his Bishop on a critical occasion. The Bishop yielded without protest, and forthwith hair began to sprout in a thousand pulpits where it had never appeared before within the memory of man.

It would be no small shock to public sentiment if our athletes in running public races were to strip themselves stark naked, yet that custom was rather suddenly introduced into Greece. Plato says (Republic V, par. 452, Jowett's translation):

Not long ago the Greeks were of the opinion, which is still generally received among the barbarians, that the sight of a naked man was ridiculous and improper, and when first the Cretans and the Lacedaemonians introduced naked exercises, the wits of that day might have ridiculed them. ... 
Thucydides (I. 6) also refers to the same change as occurring 'quite lately'.

Public opinion is commonly far in advance of private morality, because society as a whole keenly appreciates acts that tend to its advantage, and condemns those that do not. It applauds acts of heroism that perhaps not one of the applauders would be disposed to emulate. It is instructive to observe cases in which the benevolence of public opinion has outstripped that of the Law -which, for example, takes no notice of such acts as are enshrined in the parable of the good Samaritan. A man on his journey was robbed, wounded, and left by the wayside. A priest and a Levite successively pass by and take no heed of him. A Samaritan follows, takes pity, binds his wounds, and bears him to a place of safety. Public opinion keenly condemns the priest and the Levite, and praises the Samaritan, but our criminal law is indifferent to such acts. It is most severe on misadventure due to the neglect of a definite duty, but careless about those due to absence of common philanthropy. Its callousness in this respect is painfully shown in the following quotations (Kenny, Outlines of Criminal Law, I902, p. I2r, per Hawkins in Reg. v. Paine, Times, February 25, 1880):

If I saw a man who was not under my charge, taking up a tumbler of poison, I should not be guilty of any crime by not stopping him. I am under no legal obligation to protect a stranger. 
That is probably what the priest and the Levite of the parable said to themselves.

A still more emphatic example is in the Digest of Criminal Law, by Justice Sir James Stephen, 1887, p. 154. Reg. v. Smith, 2 C. and P., 449:

$A$ sees $B$ drowning and is able to help him by holding out his hand. $A$ abstains from doing so in order that $B$ may be drowned, and $B$ is drowned. $A$ has committed no offence.

It appears, from a footnote, that this case has been discussed in a striking manner by Lord Macaulay in his notes on the Indian Penal Code, which I have not yet been able to consult.

Enough has been written elsewhere by myself and others to show that whenever public opinion is strongly roused it will lead to action, however contradictory it may be to previous custom and sentiment. Considering that public opinion is guided by the sense of what best serves the interests of society as a whole, it is reasonable to expect that it will be strongly exerted in favour of Eugenics when a sufficiency of evidence shall have been collected to make the truths on which it rests plain to all. That moment has not yet arrived. Enough is already known to those who have studied the question to leave no doubt in their minds about the general results, but not enough is quantitatively known to justify legislation or other action except in extreme cases. Continued studies will be required for some 
time to come, and the pace must not be hurried. When the desired fullness of information shall have been acquired, then, and not till then, will be the fit moment to proclaim a 'Jehad,' or Holy War against customs and prejudices that impair the physical and moral qualities of our race. 
OXFORD

PRINTED AT THE CLARENDON PRESS

BY HORACE HART, M.A.

PRINTER TO THE UNIVERSITY 



\section{PLEASE do NOt REMOVE \\ CARDS OR SLIPS FROM THIS POCKET}

\section{UNIVERSITY OF TORONTO LIBRARY}

HQ

755

G35

1907

C.1

ROBA 
